\title{
Cinema hollywoodiano, a crise do pós-guerra e os cinemas novos
}

\section{Antonio Cícero Cassiano Sousa}

Doutor em história e professor e pesquisador no CEPPES (Centro de Educação Popular e Pesquisas Econômicas e Sociais), ISERJ (Instituto Superior de Educação do Rio de Janeiro e ETEAB (Escola Técnica Estadual Adolpho Bloch), Rio de Janeiro, Brasil.

\section{Resumo}

O artigo analisa os problemas enfrentados pela indústria cinematográfica estadunidense resultantes do advento da televisão como meio de comunicação de massa e de novos hábitos das camadas médias dos grandes centros urbanos; focaliza, também, as respostas a tais questões dadas pelos chamados cinemas novos.

Palavras-chave: cinema de gênero, cinema de autor, cinemas novos, cinema moderno, indústria cinematográfica.

\section{Resumen}

Este trabajo analisa los problemas que enfrenta la industria cinematográfica estadounidense como resultado de la acensión de la televisión como medio de comunicación de masa y de nuevos hábitos de las capas medias de grandes centros urbanos; además foca las respuestas a dichas cuestiones propiciadas por los llamados cines nuevos.

Palabras-llave: cine de género, cine de autor, cine nuevos, cine moderno, industria cinematografica.

\section{Abstract}

The article analyses the problems of american cinematographic industry with the advent of televison as mass media and the new costumes of midlle class of great urban centers; it focalyzes too the answer given by new cinemas.

Key words: genre film, author film, new cinemas, modern cinema, cinematographic industry. 


\section{Introdução}

$\mathrm{O}$ gênero é uma das formas mais populares de identificação dos filmes. É possível falar de um cinema de gênero que se distinguiria do cinema de autor, desde os anos 50, quando os jovens críticos e realizadores, que atuavam em torno da revista Cahiers du Cinéma, começam a valorizar a autoria, redescobrindo autores com Alfred Hitchcock e Howard Hawks, entre outros, e valorizando a produção de filmes onde a intervenção do autor seja determinante, o que daria status à onda renovadora conhecida mundialmente como cinemas novos ou cinema moderno.

O que era o cinema de gênero? Entre as inúmeras classificações de filmes, seguimos a que estabelece os seguintes grupos: drama (com o subgênero melodrama ou drama romântico) faroeste ou western, filme noir (no Brasil, a expressão é de uso restrito, noir significa preto em francês e a designação foi criada pelos críticos de cinema que associaram os filmes a cor da capa dos livros que traziam esse tipo de história), ficção científica, musical, comédia e cinema de animação. Para ilustrar, vejamos a definição de bangue-bangue, filme noir, drama romântico e o cinema de animação.

O bangue-bangue possui um eixo narrativo básico, que se traduz no conflito colono branco/índio, comunidade ordenada/grupos marginais, vingador-vingadores/vítimas. Esta narrativa se desenvolve no universo figurativo da "fronteira", tão importante no movimento de conquista do oeste americano. A mitologia criada é definida em termos de movimento, transição, mutação:

"A planície atravessada pela caravana dos colonos; os vaus para o gado; as passagens dos canyons com os perigos das emboscadas; a main street sobre a qual converge a vida da cidade ou da aldeia, mas sempre considerada lugar de passagem e de transição: aqui, por exemplo, acontecem as correrias dos fora-da-lei entre o banco e o saloon, aqui param aventureiros e aqui ocorrem os acertos de conta, aqui convivem a necessidade de estabilidade e a mobilidade da fronteira" (COSTA, 1989, pp. 101-102).

A etiqueta filme noir abriga vários subgêneros: policiais, filmes de gângster, histórias de detetive e thrillers. O traço comum é pôr em cena atos criminosos e criar em torno do crime acentuado clima de suspense. Quanto à escolha de ambientes e imagens significativas, o universo mineral (rochas, cimento, asfalto) predomina na paisagem dos portos, cabarés e áreas pobres.

Nos anos 30, se destacam o filme de gângster e o filme de detetive. O primeiro relaciona-se com a situação da sociedade americana no período da grande depressão, onde o gângster ascende à posição de herói típico na mitologia urbana. Como a analogia entre a carreira dos marginais e a do cidadão comum expõe as contradições daquela sociedade, o que pode ser visto em filmes como Scarface, vergonha de uma nação (1932), de Howard Hawks (1896-1977), Inimigo público (1931), de William Wellman (1896-1975) e Anjos de cara suja (1938), de Michael Curtiz, a censura impõe a substituição da figura do gângster pela de policiais ou detetives privados.

Se os filmes de gângster retratavam miséria, delinquência juvenil, crime organizado, um contraste claro com as promessas do capitalismo, os filmes de detetive estão cercados de ambiguidade. $\mathrm{O}$ personagem do detetive é olhado com suspeita tanto pela polícia como pelos bandidos. Humphrey Bogart que interpreta o detetive Sam 


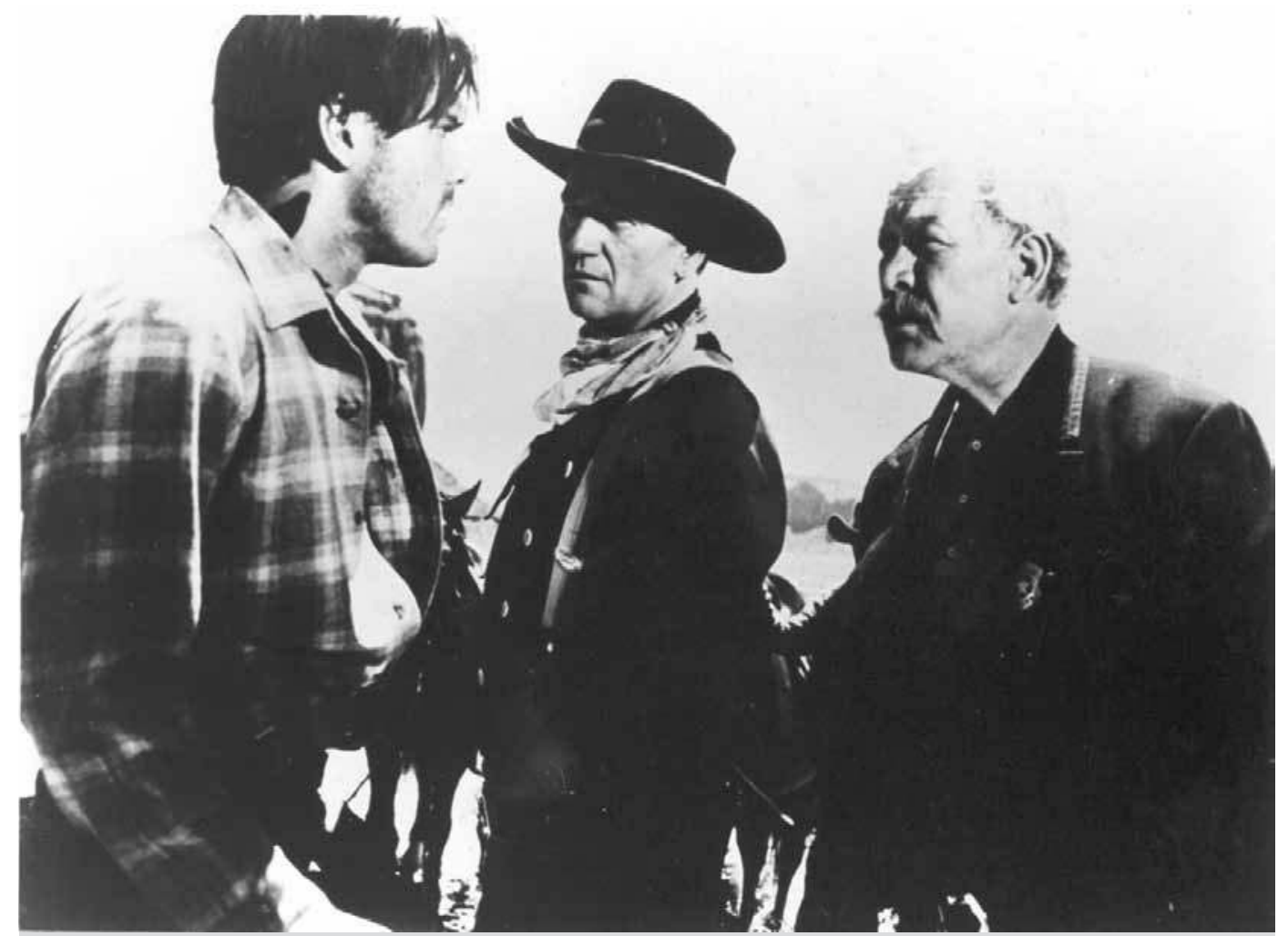

Rastros de ódio, um western de John Ford.

Spade em Relíquia macabra (1941), de John Huston (1906-1987), representa muito bem essa ambiguidade, especialmente no "melancólico distanciamento das ações em que se vê implicado" (COSTA, 1989, p. 103). O universo do crime e da violência é apresentado também como possuindo certo fascínio. E, por último, na relação que se estabelece entre a solução do enigma e uma verdade mais profunda, o herói é impotente: olhos vendados por causa de acidente e/ou corte no nariz representam esta incapacidade frente a forças que não controla mais.

Do ponto de vista narrativo, drama no cinema designa ação violenta ou patética em espaço crível; o drama romântico, por sua vez, gira em torno de um par amoroso central que irá pontuar as peripécias, as reiterações temáticas como erro de informação, coincidências, "lua de mel" no meio da narrativa, como também reiterações espaciais, com níveis diferenciados para os amantes e os demais personagens. A narrativa, frequentemente, se desenvolve em dois blocos, permitindo circularidade ou caráter cíclico. Serenata prateada (1941), de George Stevens (1904-1976), conta a história de um jovem casal que é obrigado a separar-se quando o marido é designado como corresponde de um jornal em Tóquio. Trata-se de um bom exemplo do desenvolvimento deste tipo de narrativa. $\mathrm{O}$ mundo concreto é apresentado como empecilho para a felicidade, empurrando os personagens para a ênfase subjetivista e ausência de questionamento das regras sociais (CAPUZZO, 1999, pp. 71-78).

Embora não se possa falar dele como um gênero no sentido estrito, o cinema de animação é um nicho com características muito próprias. Pode ser definido como o processo em que se dá movimento a imagens desenhadas ou fotografias de objetos inicialmente imóveis por meio de procedimentos mecânicos, eletrônicos ou digitais. 
Assim, o movimento não existe no momento de registro, como no cinema, mas é um resultado final do processo cinematográfico, obtido somente com a projeção.

A animação chegou ao público antes do cinema na forma de jogos óticos, como o praxinoscópio, taumatrópio e outros.

As técnicas de animação são inúmeras, desde o stop motion (filmagem quadro a quadro de imagens desenhadas, marionetes ou outros objetos inanimados) até a animação computadorizada. $\mathrm{O}$ desenho sobre acetatos (cel animation) permite conservar partes de um fotograma no seguinte, modificando-se apenas os elementos móveis, já o desenho sobre papel (animação plena) implica o desenho de todo o quadro para uma nova tomada. Trata-se de técnicas extremamente trabalhosas na medida em que se exige 1440 imagens para cada minuto de animação.

Com a era da informática, os sistemas de controle computadorizado do movimento se incorporaram ao manejo da câmera renovando a técnica centenária do stop motion.

\section{0 cinema durante a guerra}

No período da segunda guerra, o cinema americano continuava essencialmente a repetir os mesmos assuntos e insistir na narrativa linear. A comédia dava sinais de cansaço, a vida dos homens ilustres não era saída nem a volta do faroeste ou o musical em Technicolor ${ }^{1}$. O código Hays continuava um fator de inibição do desenvolvimento criativo dos autores.

A posição daqueles que defendiam a não participação dos Estados Unidos na guerra termina por impedir que o cinema americano possa abordar abertamente a guerra europeia. (Sadoul, 1963, p. 317). A série de documentários Por que lutamos (Why we fight), iniciada em 1942 por encomenda do governo, dirigida por Frank Kapra, Anatole Litvak e Anthony Veiller, foi esforço importante na propaganda de engajamento no conflito.

Aumentam durante a guerra os filmes de propaganda religiosa, motivados pela angústia que a guerra trazia e pela atuação da organização católica Legião da Decência, como exemplos temos Como era verde o meu vale (1941), de John Ford (1895-1973) e $A$ canção de Bernadete (1943), de Henry King.

Destacam-se no período Cidadão Kane (1941) de Orson Welles (1915-1985), Casablanca (1942), de Michael Curtiz e o trabalho de Alfred Hitchcock (1899-1980).

O novo gênio reclamado por René Clair parecia ser Orson Welles. As inovações técnicas apresentadas em Cidadão Kane: fotografias em claro-escuro, cenografias não realistas, emprego sistemático da profundidade de campo, travellings imensos apontavam para um nível de elaboração não costumeiro no cinema americano. Deve-se reconhecer nesses recursos processos antigos, provenientes alguns do expressionismo alemão, agora justificados pela narrativa e pela psicologia dos personagens (BERNADET, 1980, p. 54).

Em Hitchcock, aliam-se sucesso comercial e preocupação com a linguagem. De 1922 a 1940, realiza filmes no Reino Unido, a partir de então, fixa-se nos Estados Unidos e, em 1943, apresenta uma verdadeira obra prima, $A$ sombra de uma dúvida (1942), história de um assassino que se esconde numa cidadezinha californiana e é adorado pela sobrinha. Mais adiante falaremos da sua produção do pós-guerra.

1Technicolor é a marca registrada da empresa americana de mesmo nome; seu colorido é resultado da gravação sobre três películas diferentes, roxo, azul e amarelo, sobrepostas sobre uma quarta destinada à projeção. A partir dos 60, o uso da cor se estende com diversos processos de colorido. 
$\mathrm{Na}$ Alemanha, a ascensão de Adolf Hitler leva ao surgimento de um cinema comprometido com o nazismo: O triunfo da vontade (1936), de Leni Riefenstahl (1902-2003) apresenta os dois aspectos exaltados pelo regime, o decoro aparente e a barbárie real (Sadoul, p. 234). Nesse filme, Hitler aparece como um deus que desce dos céus em um avião cercado de nuvens.

No Brasil, o trabalho de Humberto Mauro prossegue lançando as bases do cinema nacional, agora associado à atriz, produtora e diretora portuguesa radicada no país, Carmen Santos (1904-1952), proprietária da produtora Brasil Vita Film. Nesse período, Mauro dirige Favela de meus amores (1935), Cidade mulher (1936) e Argila (1940). A partir de 1936, começa a trabalhar no Instituto Nacional do Cinema Educativo, onde realizou mais de 300 documentários e o longa-metragem $O$ descobrimento do Brasil (1936).

A grande novidade no período é o surgimento de um novo estúdio - A Atlântida, fundada, em 1941, por Moacir Fenelon (1903-1953), Alinor Azevedo (1914-1974) e José Carlos Burle (1907-1983).

\section{0 cinema mundial no pós-guerra}

Nos dois primeiros anos após a guerra, o cinema americano ainda vive certo clima de tolerância. É o liberalismo de Franklin D. Roosevelt que, embora morto em abril de 1945, teria seu nome ligado a uma fase de relativa liberdade e prosperidade que se prolonga até 1947. No outono desse ano, já no governo de Harry Truman, a Comissão de Atividades Antiamericanas do Senado retomou seu trabalho iniciado antes da guerra. Recomeçava a "caça às bruxas". Diversos profissionais de Hollywood são acusados de comunistas, condenados e presos, e outros tantos são inscritos nas listas negras e impedidos de trabalhar. Diretores como Joseph Losey (1909-1984) e Jules Dassin (1911) se exilam na Europa.

A visão de mundo apresentada por Hollywood encontra nos filmes noir um importante meio de expressão, tanto nas suas manifestações mais criativas, como em Gilda (1945), de Charles Vidor (1900-1959), ou ainda revelando aspectos mais reacionários, presentes em Ninguém crê em mim (1949). Assim Sadoul (1904) define Hollywood, no período da "caça às bruxas":

"Acobertada pelo código do pudor e com o assentimento da 'Legion of decency', Hollywood mostrava um mundo povoado de bipócritas, sádicos, assassinos, policiais corrompidos, pequenos escroques e semiprostitutas. Podia-se concluir dessas fitas que a humanidade é bem desprezivel e que seu formigueiro merecia ser aniquilado sem remissão sob um calcanhar de ferro atômico" (SADOUL, 1963, pp. 351-352).

No final dos 40, dois golpes atingem esse sistema: em 1948, a Corte Suprema decreta a ilegalidade do sistema de monopólios e a televisão começa a se popularizar rapidamente. Em 1950, o número de televisores instalados chega a 5 milhões.

No imediato pós-guerra, o cinema soviético volta-se para temas divertidos e alegres. Em 1946, o Pravda critica o relaxamento da produção, dando lugar a obras exaltativas dos feitos da Segunda Guerra. Até a primeira metade dos anos 50, o Ministério do Cinema exerceu papel ativo na produção. Após 1956, o cinema soviético segue novo 


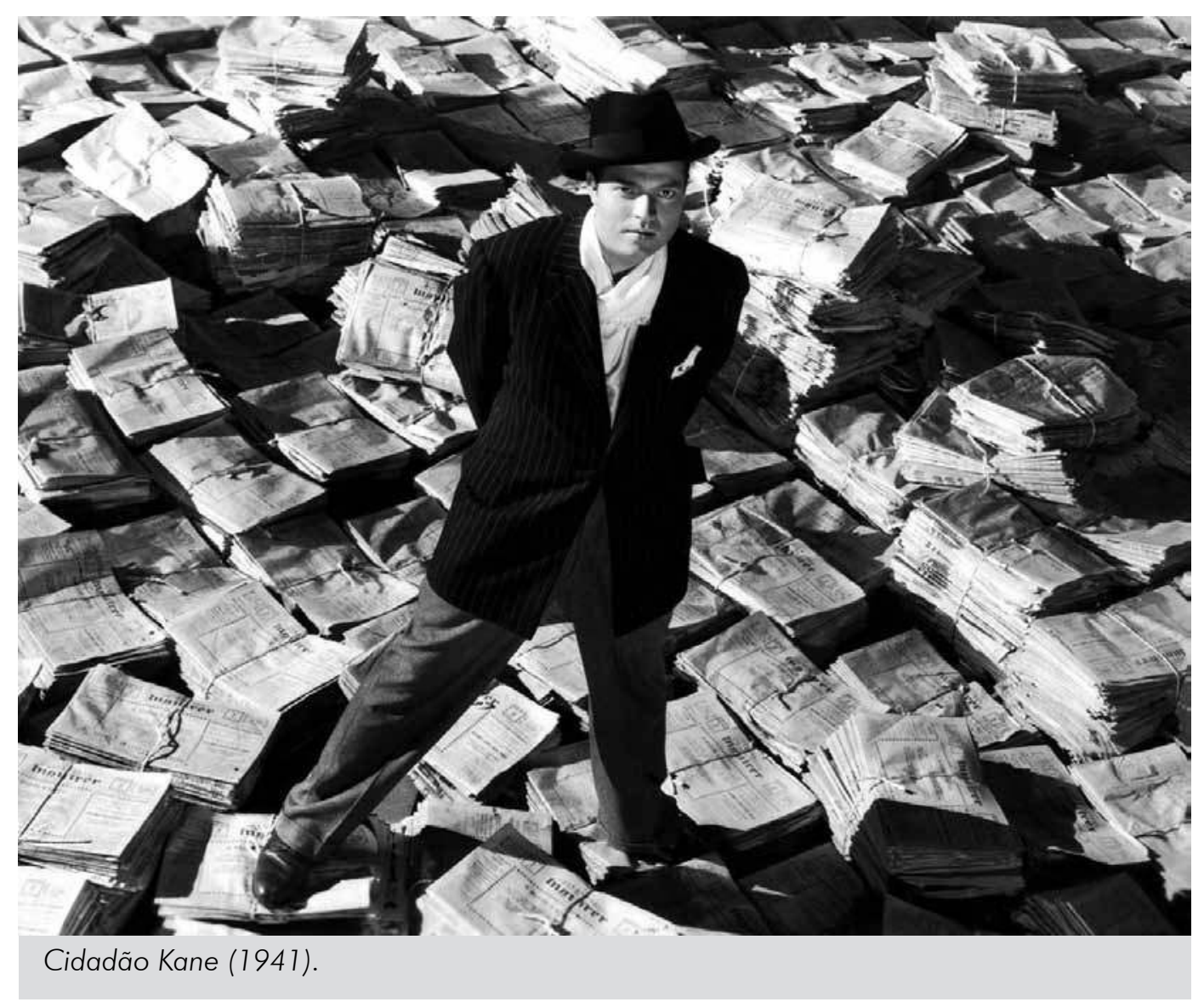

curso, quando se destacam Quando voam as cegonhas (1957), de Mikhail Kalatozov (1903-1973) e A balada do soldado (1959), de Gregori Tchukhrai (1921).

\subsection{0 neorrealismo italiano}

É na Itália do pós-guerra que o cinema vai renascer. Ainda durante a guerra surge Obssessione (1942), de Luchino Visconti (1906-1976), inspirado livremente no romance de James Cain, The postman rings twice. ${ }^{2}$ Em 1945, Roberto Rosselini (1906-1977) lança Roma, cidade aberta, e em 1946, Vittorio de Sica (1901-1974), com roteiro de Cesare Zavatini, apresenta Vitimas da tormenta (1945-1946). A influência do marxismo, especialmente, através de Zavatini, e a luta contra o fascismo forneceram elementos básicos para a eclosão do movimento. A luta da resistência aparece particularmente nos filmes de Rosselini. De Sica e Zavatini vão desenvolver a crítica da sociedade italiana do pós-guerra: os pequenos trabalhadores das ruas (Vitimas da tormenta), o desemprego (Ladrões de bicicleta, 1948), o drama dos aposentados na luta por uma vida digna (Umberto D, 1951). Federico Fellini (1920-1991), que inicialmente trabalhou com Rosselini, contribuiu especialmente com os filmes Abismo de um sonho (1952), Os boas-vidas (1953) e A estrada (1954).

O neorrealismo vem mostrar que é possível recriar o cinema fora dos padrões hollywoodianos. Suas características marcantes seriam a filmagem em externas, uso frequente de atores não profissionais, roteiros com personagem simples e ação em

2 Bob Rafelson realizou em 1981 uma nova versão intitulada O destino bate a sua porta, com Jack Nicholson e Jessica Lange. 
ritmo compassado, ao contrário dos acontecimentos espetaculares do filme comercial (AUMONT, 1995, p. 136).

No final dos anos 50, o movimento entrava em declínio por duas razões essenciais: o clima de repressão com a chegada da democracia cristã ao poder e os caminhos próprios seguidos pelos participantes da escola.

\subsection{Atlântida e Vera Cruz: tentativas de cinema industrial no Brasil}

De 1941 a 1947, a produção da Atlântida varia de romances a questões sociais, passando neste ano a produzir comédias musicais que ficarão conhecidas como chanchadas ${ }^{3}$. Com a entrada na empresa de Luís Severiano Ribeiro, um dos maiores exibidores do Brasil, o problema permanente da exibição é resolvido, garantindo o tão almejado espaço exibidor.

Watson Macedo (1918-1981) e Carlos Manga (1928) formam a dobradinha de diretores responsáveis pelos maiores sucessos da Atlântida. Macedo dirigiu Este mundo é um pandeiro (1947), Carnaval no fogo (1949), O petróleo é nosso (1954) e outros. Manga dirigiu alguns sucessos como, Nem Sansão, nem Dalila (1953), Matar ou correr (1954) e O homem do Sputnik (1959). Embora a referência seja o cinema hollywoodiano, as comédias da Atlântida têm vida própria, pois o padrão americano não é levado a sério, o que acaba conferindo certo tom de crítica ao colonialismo cultural. Por outro lado, o povo começava a se ver no cinema através dos tipos representados por Grande Otelo (1915-1993) e Oscarito (1906-1970).

Fundada em 1949, a Vera Cruz, por sua vez, pretende reproduzir com realismo o modelo americano. A ideia inicial era que os novos estúdios produzissem dez filmes por ano. Mesmo apoiada por uma sólida base financeira, problemas com a distribuição e ausência de uma linguagem popular fizeram a Vera Cruz encerrar suas atividades em 1954. Entre outros méritos, tornou possível o retorno de Alberto Cavalcanti (1897-1982) ao Brasil, a vinda de inúmeros técnicos estrangeiros que ofereceram importantes contribuições à produção nacional, e lançou o cinema brasileiro no exterior com O cangaceiro (1953), de Lima Barreto (1906-1982), distribuído em mais de oitenta países e premiado como o melhor filme de aventuras no Festival de Cannes.

Além da Atlântida e o ciclo da Vera Cruz, a presença de Humberto Mauro se faz sentir no trabalho de documentarista que realiza para o Instituto Nacional do Cinema Educativo e de seu último longa metragem, Canto da saudade (1952), onde se destacam as belas imagens estilizadas.

\subsection{Os cinemas novos}

Não há um consenso na denominação que deve receber este período que se abre com o aparecimento da nouvelle vague (nova onda) francesa no final dos anos cinquenta. A expressão novo é usada com muita frequência, mas se usa também "cinema moderno”. Antonio Costa, com base em L. Miccichè, crítico italiano, apresenta quatro traços comuns desse cinema:

3Chanchada significa coisa mal feita. A conotação pejorativa vai se perdendo em razão da boa receptividade do público. 
. estrutura narrativa próxima das novas tendências literárias, afastando-se da transposição para a tela das técnicas do romance do século XIX, como Griffith fazia; o modelo literário passa a ser o novo romance de narrativa não linear;

- a linguagem fílmica deveria ser anti-naturalista e evidenciar a subjetividade do autor;

- ideologia não explícita, apresentada sob formas fluidas e indiretas, baseada em metáforas e alegorias;

- mudanças na estrutura de produção visando maior controle por parte dos autores (COSTA, pp. 119-120).

No Brasil, as primeiras preocupações neste sentido aparecem com Agulha no palheiro (1952) de Alex Viany (1918-1992). Neste filme já estão presentes aspectos do neorrealismo que influenciarão os novos rumos do nosso cinema. Rio 40 graus (1955), de Nelson Pereira dos Santos (1928) e O grande momento (1958), de Roberto Santos (1927-1987) dão início a uma fase criativa e em busca de sintonia com o público, por mais que este objetivo tenha custado a se concretizar.

Até 1964, a temática predominante era o mundo rural ou a miséria urbana, representada pela favela. $\mathrm{Na}$ abordagem do drama rural, merecem destaque Vidas secas (1963), de Nelson Pereira dos Santos, e Deus e o diabo na terra do sol (1964), de Glauber Rocha (1939-1981). Cinco vezes favela (1962), produzido pelo CPC da UNE (Centro Popular de Cultura da União Nacional dos Estudantes) é um ensaio de uma nova proposta na relação com o público e de experimentação para novos cineastas como Cacá Diegues (1940), Joaquim Pedro de Andrade (1932-1988), Leon Hirszman (1937-1987) e Miguel Borges (1937). O assalto ao trem pagador (1962), de Roberto Faria (1932) e Orfeu do Carnaval (1959), dirigido pelo francês Marcel Camus (1912-1982) se voltam para a situação nas favelas do Rio de Janeiro, enquanto Opagador de promessas (1962), de Anselmo Duarte conjuga os dois mundos em torno do problema do sincretismo religioso, ganhando a Palma de Ouro daquele ano. Com o golpe de 1964, a desilusão com a estratégia de aliança com a burguesia nacional leva a novas reflexões sobre o papel da classe média. Filmes como O desafio (1965), de Paulo César Saraceni (1933), e Terra em transe (1967), de Glauber Rocha, são exemplos dessa tentativa da classe média refletir sobre sua situação e seus enganos quanto à aliança com a chamada burguesia nacional.

O cinema novo brasileiro é parte de um movimento continental, que é o cinema novo latino-americano formado, entre outros, pelo cinema novo argentino e o cinema revolucionário cubano. As características comuns desse cinema voltam-se para uma ruptura com as práticas do cinema industrial tradicional, o que significa a incorporação de um projeto de mudança social radical e não a simples busca de coerência estilística e temática. Miguel Littin (Por la tierra ajena, 1965, Atas de Marusia, 1975, e Sandino, 1989) no Chile, Tomás Gutierrez Alea (A morte de um burocrata, 1966, e Memórias do subdesenvolvimento, 1968) em Cuba, Jorge Sanjines (O sangue do condor, 1969) na Bolívia, Fernando Solanas (La hora de los hornos, 1966/1968) na Argentina e os brasileiros Nelson Pereira dos Santos e Glauber Rocha são os nomes mais expressivos.

O movimento é atingido seriamente com o advento das ditaduras militares na região, o declínio dos ideais do período e a adesão de alguns cineastas ao cinema industrial tradicional.

Ao contrário do neorrealismo italiano, a nouvelle vague francesa se manterá mais distante dos problemas sociais, enfatizando um cinema voltado para questões existen- 


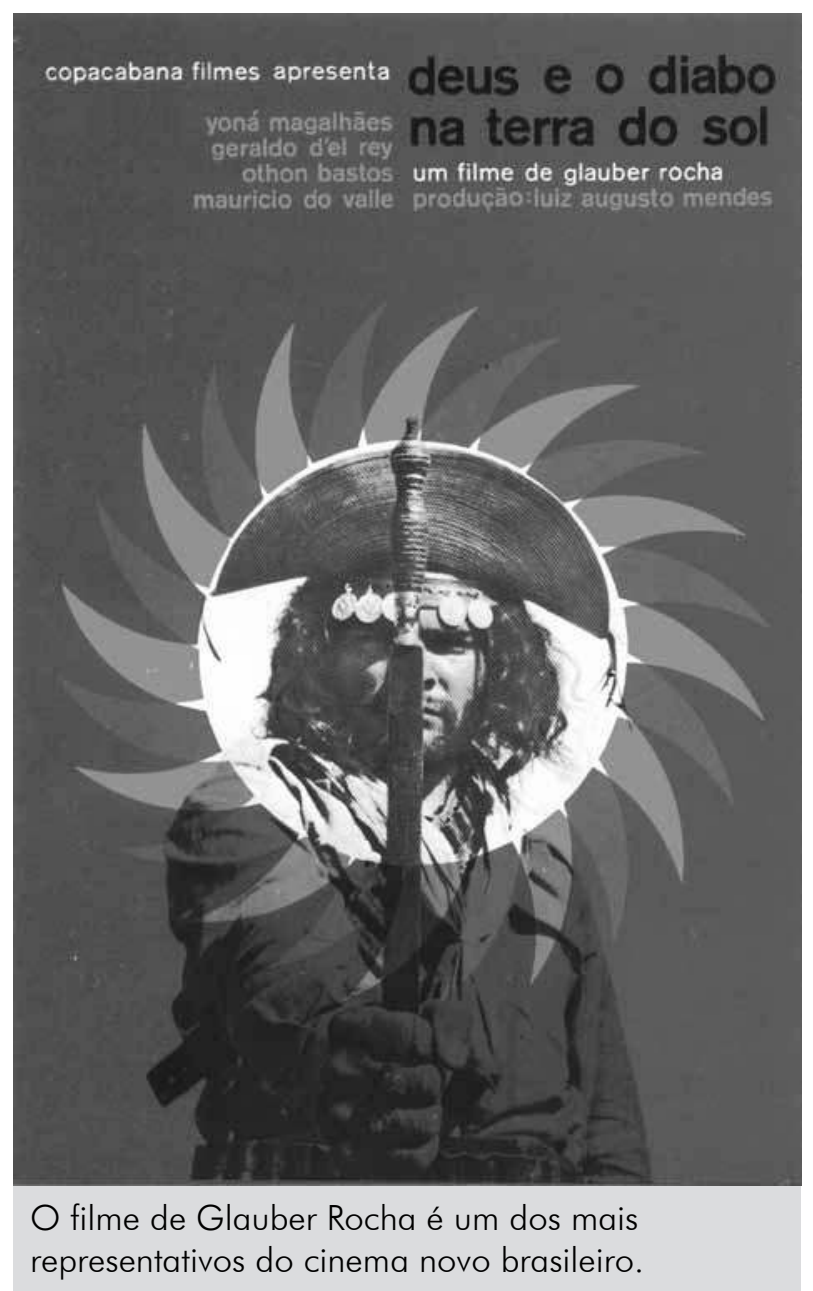

ciais. A sua origem está num grupo de críticos de cinema da revista Cabiers du cinema, o que permite uma tomada de consciência do meio utilizado. De forma provocativa, assim Jean-Luc Godard (1930) se refere a essa condição especial do grupo: "Nós somos os primeiros cineastas a saber que Griffith existe" (COSTA, 1989 p. 121).O seu filme Acossado (1960) é um manifesto dessa nova concepção.

Da mesma forma que a escola italiana, a nouvelle vague evolui abrindo caminhos bastante distintos: Alain Resnais (1922), Eric Rohmer (1920) e Jean-Luc Godard mantêm uma linha de questionamento,já Claude Chabrol (1930) e François Truffaut (1932-1984) dão continuidade a um cinema não muito diferente daquele que tinham se oposto no início.

A principal tradição cinematográfica do Reino Unido é a do filme documentário. A renovação do cinema britânico vem deste setor. $\mathrm{O}$ movimento que fica conhecido como free cinema surge com a produção de curtas metragens apoiados pelo British Film Institute, entre 1956 e 1959. A responsabilidade social do artista e apresentação de problemas do cotidiano, especialmente da classe operária, são preocupações iniciais do grupo. Após uma breve onda, os limites entre cinema acentuadamente comercial e o free cinema se diluem e o movimento entra em declínio. Lindsay Anderson (19231994), autor de filmes como Se ... 1968) e As baleias de agosto (1988), é considerado o mais questionador. Também participaram dessa renovação do cinema britânico, Tony Richardson (1928-1991), diretor de Tom Jones (1962), entre outros, e Karel Reisz (1926), que dirigiu Tudo comę̧ou no sábado (1960), o manifesto do movimento, e $A$ mulher do tenente francês (1981), entre outras obras importantes. 
A renovação no cinema americano tem início com a fundação do New american cinema group, em 1960, em Nova Iorque. Sintonizada com as vanguardas artísticas e desvinculada da distribuição tradicional, essa produção toma dois caminhos: um grupo propõe a retomada da narrativa impregnada agora de um novo realismo, mostrando a América pobre e não se furtando a examinar a sordidez da economia de mercado. São exemplos os trabalhos de Shirley Clarke (1925), The connection (1960) e Cool world (1963), de John Cassavetes (1929-1989), Shadows (1960) e de Lionel Rogosin (1924), The bowery (1955); outra corrente desenvolve um cinema experimental desvinculado de preocupações sociais, mais influenciado pela vanguarda literária, teatral e musical, representado por Andy Warhol (1928-1987).

Há duas cinematografias que coincidem cronologicamente com esta onda de renovação e elas próprias possuidoras de importantes elementos criativos, mas ao mesmo tempo muito particulares: os cinemas do sueco Ingmar Bergman (1918) e do japonês Akira Kurosawa (1910-1998). Marcado por sua experiência no teatro, Bergman valoriza acentuadamente a direção dos atores, obtendo primorosas interpretações. A fotografia esteve sempre a cargo de Sven Nykvist, o que contribui para a unidade estética de seus filmes. Os temas estão marcados pela biografia do autor, variando desde questões existenciais e filosóficas (O sétimo selo, 1957, Gritos e sussurros, 1974), problemas conjugais (Cenas de um casamento, 1975), passando pela reflexão sobre a própria arte (Persona, 1966). Curiosamente é em seu exílio hollywoodiano que Bergman vai revelar preocupações políticas de forma explícita: Ovo da serpente (1979) aborda a situação da Alemanha às vésperas da ascensão do nazismo.

Em 1952, Rashomon (1950), de Akira Kurosawa, recebe o Oscar de melhor filme estrangeiro e o Ocidente descobre o cinema japonês. Influenciado por Ford, Hawks, Gance, Capra e Wyler, Kurosawa é o mais ocidental dos cineastas japoneses. Adaptou obras de Shakespeare como Macbeth (Trono manchado de sangue, 1957), por outro lado, a trama de Os setes samurais (1954) foi transposta para o Oeste americano em Sete homens e um destino (1960), dirigido por John Sturges. Na obra de Kurosawa, a violência explode como resposta às injustiças sociais, revelando sempre um profundo humanismo.

O período que vai do final dos anos 40 até o início dos 70 é marcado por profunda crise do cinema comercial americano. $\mathrm{O}$ declínio está associado a um conjunto de fatores: disseminação da televisão, novos hábitos introduzidos na classe média com o acesso ao automóvel e a eterna subestimação da capacidade do público.

Quanto ao público, houve duas modificações básicas: a primeira foi a sua diminuição em termos astronômicos, variando conforme os novos hábitos iam sendo implantados:

- nos Estados Unidos, em 1946, ano do pico na assistência, registra-se 4 bilhões e meio de espectadores, em 1976, a cifra desce para 948 milhões, uma queda de $78 \%$;

- na Itália, dos 819 milhões de ingressos vendidos em 1955, auge da expansão, se passa para 454 milhões em 1976 e 162 milhões em 1983 (Costa, p. 133);

- para o Brasil não temos dados sobre o auge da assistência, que deve ter ocorrido também na década de 50, mais recentemente a frequência caiu de 250 milhões de espectadores por ano, nas décadas de 70 e 80, para 90 milhões em 1996 (MARINGONI, 1996, p. 81). 
Além do declínio vertiginoso, o público se fragmenta. Forma-se um público majoritário, situado entre os 12 e 24 , e outros setores especializados: filmes de autor, cult movies ${ }^{4}$ filmes pornográficos etc.

Antonio Costa chama a atenção para outro componente dessa crise estrutural do cinema. Trata-se do fim do sistema de produção baseada no produto médio com as articulações em vários níveis (filmes $\mathrm{A}$ e B, filmes de autor etc.). Agora os filmes são individuais, têm identidade própria e são vendidos com camisetas, brinquedos, outras mídias etc.

As tentativas de ampliar o público, limitadas ao plano puramente técnico, como filmes em três dimensões, telas panorâmicas, foram insuficientes.

\subsection{A nova Hollywood}

A renovação do cinema americano dos anos 70 está associada a um conjunto de fatores:

- revisão ideológica (e renovação estética) dos gêneros clássicos, a partir do final dos anos 60, cujo alvo principal foi o faroeste; os melhores exemplos são Meu ódio será sua herança (1969), de Sam Peckinpah (1926-1984), Quando épreciso ser homem (1969), de Ralph Nelson (1916-1988), Pequeno grande homem (1970), de Arthur Penn (1922) e Quando os homens são homens (1971), de Robert Altman (1925); a nova abordagem abandona o maniqueísmo predominante no período anterior e apresenta os povos originários como alvo da pilhagem dos conquistadores de origem europeia.

- atualização da iconografia dos gêneros tradicionais, especialmente, o filme noir, alguns exemplos: Sexy e marginal (1972), de Martin Scorsese (1942), A conversação (1974), de Francis Ford Coppola (1939), Klute: o passado condena (1971), de Alan Pakula (1928) e Os três dias de condor (1975), de Sidney Pollack (1935 ); nesta retomada, se sobressai o hiper-realismo - um excesso de evidência típico dos filmes americanos dos anos 70.

- mistura dos gêneros e integração de tecnologias; exemplos: a filmografia de George Lucas (1945) a partir de Guerra nas estrelas (1977) e de Steven Spielberg (1947) ) a partir de Contatos imediatos de $3^{\circ}$ grau (1977); nos anos 70, o fenômeno da mistura dos gêneros se radicaliza e o uso de alta tecnologia, que antes se localizava na ficção científica, se dissemina.

- $\quad$ integração entre produção independente e estruturas de distribuição controladas pelas corporações, constituindo a base da renovação do cinema norte-americano: Sem destino (1969), de Dennis Hopper (1936), produção independente distribuída pela Columbia que custou quatrocentos mil dólares, rendeu à distribuição 19 milhões (COSTA, 1989, pp. 136-140).

Esta renovação da produção hollywoodiana recorre ao emprego de novas tecnologias, adota concepção ideológica progressista, em seu aspecto geral, e retoma antigas tradições.

4Cult movies são filmes acompanhados por um público que lhes dedicam vivo interesse. 


\section{Conclusões}

Pode-se afirmar que a onda renovadora parte da periferia no final dos anos $40 \mathrm{e}$ atinge seu ápice nos anos 70, ao atingir a produção estadunidense, permitindo falar em Nova Hollywood. A renovação, no entanto, enfrenta dois problemas cruciais: o domínio dos monopólios, por um lado, incorpora partes dos jovens realizadores, domesticando sua capacidade produtiva, por outro, recorre à censura e/ou à perseguição política com o recurso da tortura e do extermínio físico, particularmente nos países da periferia; mas há outra questão não menos importante: a própria linguagem cinematográfica envelhece muito rapidamente, exigindo padrões inconciliáveis com a produção capitalista. A popularização do vídeo nos anos 70 e 80 aprofunda a crise da recepção, produzindo o ambiente de saturação de imagens e sons para não serem vistos ou ouvidos: uma educação audiovisual para esquecer e reduzir a capacidade reflexiva.

\section{Referências bibliográficas}

AUMONT, Jacques e outros. A estética do filme. Trad. Marina Appenzeller. São Paulo, Papirus, 1995

BERNADET, Jean-Claude. O que é cinema. São Paulo, Brasiliense, 1980 (Coleção Primeiros Passos).

CAPUZZO, Heitor. Lágrimas de luz: o drama romântico no cinema. Belo Horizonte, Ed. UFMG/Laboratório Multimídia da UFMG, 1999.

COSTA, Antonio. Compreender o cinema. 2a . ed. Trad. Nilson Louzada. Rio de Janeiro: Globo, 1989.

MARINGONI, Gilberto. A guerra nas telas. Atenção, São Paulo (9): 78-81, novembro de 1996.

SADOUL, Georges. História do cinema mundial.Trad. Sônia S. Gomes. São Paulo, Martins Fontes, 1963 (?), vol. I e II.

TURNER, Graeme. Cinema como prática social. Trad. Mauro Silva. São Paulo: Summus, 1997. 